\title{
Effect of dietary water content on European sea bass (Dicentrarchus labrax) growth and disease resistance
}

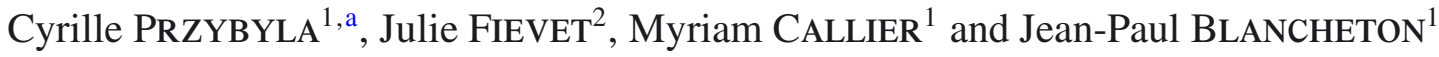 \\ 1 IFREMER, Unité Biologie des organismes marins exploités, UMR 5119 Ecosym, Chemin de Maguelone, 34250 Palavas les Flots, France \\ 2 IFREMER, Centre du Pacifique, Unité Ressources marines en Polynésie Française, Taravao, Tahiti, French Polynesia
}

Received 16 July 2014; Accepted 24 October 2014

\begin{abstract}
The effect of dietary water content on Dicentrarchus labrax growth parameters and resistance to Vibrio anguillarum infection was investigated using commercial pellets with identical energy contents and different moisture levels. The first experiment hypothesis was that moisturizing pelleted ration can have an impact on Dicentrarchus labrax growth performance by the osmoregulation energy cost reduction. In a second time, the experiment explores the effect of water addition in pellets on the fish resistance to a disease. A specific device was built to uniformly moisturize dry pellets to different moisture levels, i.e. $8 \%, 20 \%, 40 \%$ and $60 \%$. After an acclimation period and a 54-day rearing period, the control fish had grown from $72.7 \pm 17.9 \mathrm{~g}$ to $133.3 \pm 29.4 \mathrm{~g}$. No significant differences were recorded for fish growth parameters. After the growth period, the tagged fish were mixed and challenged by bath exposure to live Vibrio anguillarum in triplicate. After 7 days, mortality was significantly lower in the group of fish fed with pellets containing $60 \%$ water. Adding water to Dicentrarchus labrax feed did not affect fish growth parameters but increase its resistance to a Vibrio anguillarum infection. The moisturizing process could be used to add specific compounds (such as probiotics or vitamins) to pellets just before fish feeding and could have a positive effect on fish rearing.
\end{abstract}

Keywords: Fish aquaculture / Dietary moisture content / Feed pellets / Fish growth / Immunity / Dicentrarchus labrax / Vibrio anguillarum

\section{Introduction}

The expected development of fish aquaculture in the next thirty years and the decrease in fresh water quality and availability are strong arguments in favour of the development of marine fish production. Aquaculture feed accounts for approximately $50 \%$ of fish production costs worldwide (Rana et al. 2009). In modern aquaculture, fish are fed using extruded pellets. This type of diet is associated with nutritional balance, stable energy levels and controlled nutrient quality. However, because of the formulas and process used, extruded pellets are very hard. In Europe, the legal water content in animal feed is less than $10 \%$ (European-Union 2009). This allows biochemical stability to be maintained during transportation and storage. A large proportion of farmed fish around the world are fed dry pellets with high and stable energy contents and low moisture levels. This contrasts with the $70-80 \%$ water content of natural preys (Kristiansen and Rankin 2001; Ruohonen et al. 1998a). Fish guts are adapted to digesting preys with a high water content (Buddington et al. 1997).

Dry pellet consumption imposes to a demand for water on fish, which is partly met through drinking and swimming (Ruohonen et al. 1997). Drinking rates vary according to the

\footnotetext{
${ }^{a}$ Corresponding author: cyrille.przybyla@ifremer.fr
}

fish life-stage (Ruohonen et al. 1997; Tytler et al. 1990) and feed uptake rhythm. An unfed trout drinks four times less than a fed one (Kristiansen and Rankin 2001).

Dietary water content has a direct effect on the digestive activity of fish and especially on gastric residence time. The food needs to be moisturized in the digestive tract from $10 \%$ (dry pellets) to $63-76 \%$ for the digestion process to start (Hughes and Barrows 1990; Kristiansen and Rankin 2001). Fish digestion starts between 2 to $4 \mathrm{~h}$ after meals consisting of commercial pellets (Chatzifotis et al. 2005; Ruohonen et al. 1997). Regarding the whole body composition of fish, the water content of cultured fish fluctuates between $63 \%$ (Kaushik et al. 2004) and 76\% (Van Ham et al. 2003). Water in the fish digestive tract mainly derives from diet, water ingested through drinking and stomach secretions. Ingested water and stomach secretions contribute, respectively 25-35\% and 34$44 \%$ to stomach water (Kristiansen and Rankin 2001).

Marine organisms such as marine fish have adapted their physiology to compensate for water losses (Quinton 1912) due to osmotic pressure differences between their bodies (around $320 \mathrm{mOsm} \mathrm{kg}^{-1}$, salinity 10) and the saline environment they live in (around $1000 \mathrm{mOsm} \mathrm{kg}^{-1}$, salinity 35). Fish need to drink the water surrounding them to avoid dehydration due to osmoregulation (Whittamore 2012). The marine teleost 
intestine absorbs a hypertonic fluid to compensate for fluid lost by diffusion into the marine environment (Heuer et al. 2012). Finally, fish need to increase their drinking rate by swimming for the meal hydration process and to compensate for water losses.

The positive effect of dietary water content has already been demonstrated in different fish aquaculture studies. A few publications describe aquaculture fish growth and the results are variable. No effect on fish growth parameters was observed for salmonids (Hughes and Barrows 1990; Ruohonen et al. 1997; Ruohonen et al. 1998a) and marine species such as Sebastes schlegeli (Lee et al. 2000), Lates calcarifer (Chou 1984) and Psetta maxima (Bromley 1980). On the other hand, a positive effect was found for some marine species such as Psetta maxima (Bromley 1980; Grove et al. 2001), Dentex dentex (Chatzifotis et al. 2005), Seriola dumerilii (Papadakis et al. 2008) and Solea solea (Schneider 2009).

The marine teleost digestive tract plays a triple role as a food processor, an osmoregulation organ and a protective barrier against bacteria (Nikolopoulou et al. 2011; Mouchet et al. 2012). The objective of this study was to investigate the effect of commercial pellets with increased moisture content (20\%, 40\%, 60\%, control 8\%) on European sea bass (Dicentrarchus labrax) growth using the hypothesis that the reduction in swimming could be converted into growth. The second objective was to assess the resistance of fish fed for 54 days with feeds with different water contents and then challenged by bath exposure to Vibrio anguillarum infection, the point being to observe the resistance of the fish to a vibriosis, but not in terms of pathological mechanisms. The hypothesis used for the challenge experiment was that immune system may possibly be stimulated by the water addition in fish feed.

\section{Materials and methods}

\subsection{Experimental rearing system}

The experiment was carried out in a stable environment using a recirculating aquaculture system (RAS- $25 \mathrm{~m}^{3}$ ) with a UV unit $\left(33 \mathrm{~mJ} \mathrm{~cm}^{-2}\right)$, mechanical and biological filters $\left(0.7 \mathrm{~m}^{3}\right)$ and a carbon dioxide degassing column. Twelve self-cleaning circular tanks $\left(1 \mathrm{~m}^{3}\right)$ were used. The oxygen concentration was maintained at $90 \%$ saturation for optimal fish growth (Pichavant et al. 2001) and measured at the tank outlets. The temperature of the water was maintained at $21.9 \pm 0.7^{\circ} \mathrm{C}$ in an optimal range for European sea bass growth (Person-Le Ruyet et al. 2004). The photoperiod was $16 \mathrm{~h} /$ day of light and was kept constant throughout the experiment. The RAS water replacement rate was 0.5 to $1 \mathrm{~m}^{3} \mathrm{~h}^{-1}$. Each tank was connected to a $23-\mathrm{L}$ individual particle trap for the collection of faeces and the estimation of non-ingested pellets.

\subsection{Water quality parameters}

Temperature, salinity and $\mathrm{pH}$ were measured daily in the storage tank of the RAS using a handheld WTW Cond 315i device and an Ecoscan ${ }^{\circledR} \mathrm{pH}$ meter. Oxygen concentrations were recorded continuously in the particle traps of each tank using a YSI 550A dissolved oxygen meter with Oxyguard ${ }^{\circledR}$ probes. Water samples were taken from the experimental system twice a week, filtered through glass-fibre filters $\left(\mathrm{GF} / \mathrm{C}\right.$ Whatmann $\left.{ }^{\circledR}\right)$ and then analyzed the same day for total ammonia nitrogen (TAN) using the method described by Solorzano (1969). Nitrite concentrations were determined using the molecular absorption method described by Bendschneider and Robinson (1952) and nitrate concentrations were measured using the same method after nitrite reduction using a cadmium column (Wood 1967). The average concentration $\left(\mathrm{mg} \mathrm{L}^{-1}\right)$ of nitrogen compounds as ammonia $(0.28 \pm 0.12)$, nitrite $(0.15 \pm 0.09$, nitrate $(4.08 \pm 1.91)$, urea $(0.15 \pm 0.09)$ and phosphates $(0.25 \pm 0.1)$ were monitored in a safe range in the experimental RAS.

\subsection{Experimental feed}

\subsubsection{Experimental feed support}

Commercial pellets (proteins $44 \%$, lipids $16 \%$, ash $7 \%$, energy 20.2 MJ) from an identical batch were used for the experiment (acclimation and experimental period). The experiment required water to be added to the dry matter. The commercial feed was selected for its low lipid content which made it less hydrophobic. For aquafeed with highest lipids contents the experiment can be done with a process adjustment like increasing the depression intensity and the contact time between pellets and water. The volume of water added to the feed was calculated to reach $20 \%\left(\mathrm{M}_{20}\right), 40 \%\left(\mathrm{M}_{40}\right)$ and $60 \%\left(\mathrm{M}_{60}\right)$ of the feed weight. The commercial pellets contain $8 \%\left(\mathrm{M}_{8}\right)$ moisture and were used as the control feed.

\subsubsection{Feed moisturizing method}

A specific and original device was used to increase pellet moisturizing efficacy. Nine graduated glass tubes (precision $0.1 \mathrm{ml}$ ) joined with a hermetic junction to a Nalgene ${ }^{\circledR}$ filtration unit (pellets container) were linked to a vacuum pump (Fig. 1). Identical volumes of pellets were kept under pressure $(0.7-0.8$ bar) without adding water for five minutes to remove part of the air contained in the pellets. The volume of the pellets increased slightly due to the vacuum. Different volumes of water, calculated to achieve $20 \%\left(\mathrm{M}_{20}\right), 40 \%\left(\mathrm{M}_{40}\right)$, and $60 \%\left(\mathrm{M}_{60}\right)$ moisture, were then added to the pellets. The pellets and water were kept under pressure for ten minutes. When pressure stopped being applied, the volume of the pellets decreased trapping the water inside the pellets. The $\mathrm{M}_{8}$ control pellets were not treated. The moisturizing process increased pellet volume slightly and changed the colour of the pellets from dark brown $\left(\mathrm{M}_{8}\right)$ to light brown $\left(\mathrm{M}_{60}\right)$. The water added into the containers was uniformly trapped. All the $\mathbf{M}_{60}$, pellets were evenly moisturized.

\subsubsection{Feeding strategy}

Fish satiety depends on the capacity of the fish stomach (Gwyther and Grove 1981). The addition of water increased 


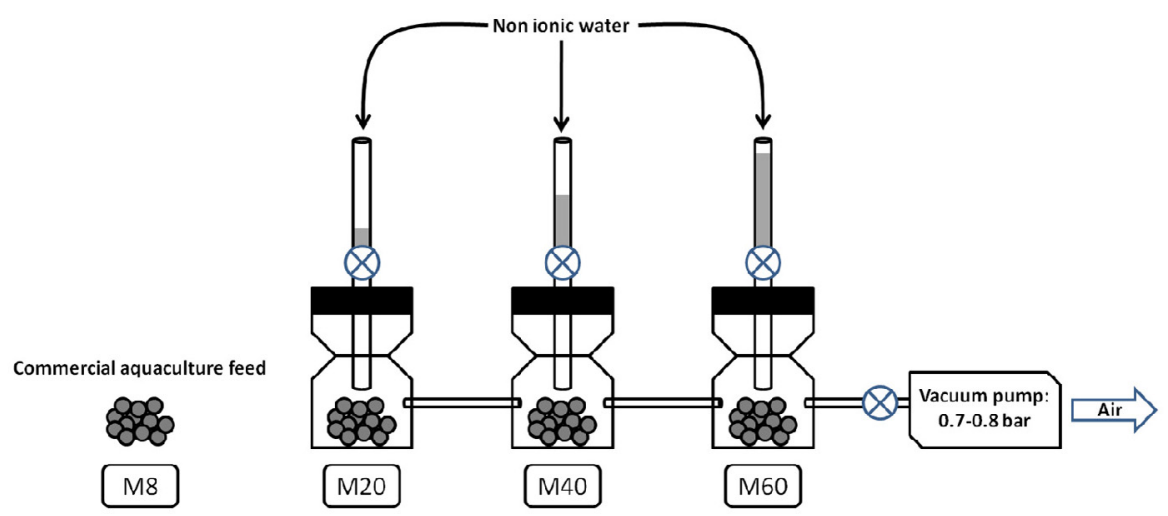

Fig. 1. Experimental system for pellet moisturization from $8 \%$ to $60 \%$ water content.

pellet size. For identical feed volumes, moisturized pellets contain less energy than dry pellets. Fish are able to compensate a lack of energy related to dietary water content by increasing their feed intake (Grove et al. 2001; Ruohonen et al. 1998b). For this experiment, fish were all the same size and therefore their stomach volumes were assumed to be identical. For a same initial feed volume (dry matter), fish fed with $\mathrm{M}_{60}$ pellets have been satiated before those given the $\mathrm{M}_{8}, \mathrm{M}_{20}$, and $\mathrm{M}_{40}$ pellets because of the high water content of the pellets. In order to avoid different feed rhythms and compare fish growth, the feeding strategy was to deliver the same energy and the same amount of pellets. A fixed restricted ration was distributed for all conditions (calculated in dry matter) adjusted and based on the average $\mathrm{M}_{60}$ fish intake. The experimental protocol took into account that the fish feed intake of the control treatment $\mathrm{M}_{8}$ was suboptimal compared to a classic feeding.

\subsubsection{Moisturized pellets distribution}

Moisturized meals were prepared daily to avoid freezing which may induce nutritional changes such as protein denaturation. Meals were distributed manually over $2 \mathrm{~h}$ to preserve pellet moisture stability while respecting fish demand. During feeding, the moisturized pellets were kept in an airtight box to avoid water evaporation. Uneaten pellets were trapped in the particle trap of each tank, counted and converted daily into dry matter to evaluate the non-ingested food volume. Meal sizes were adjusted frequently according to the increasing biomass. The amount of protein and lipids provided daily to the fish was the same for all conditions for 54 days.

\subsection{Fish population and acclimation period}

The European sea bass were produced by the Palavas IFREMER station from non-inbred stock. The fish were individually tagged $(n=590)$ with passive integrated transponder tags. Forty-seven to fifty fish $(62.7 \pm 2.4 \mathrm{~g})$ were distributed into twelve tanks (arranged in triplicate for each treatment). Tank distribution was calculated so the same biomass $(3.5 \pm$ $0.2 \mathrm{~kg} \mathrm{~m}^{-3}$ ) would be achieved at non-stressful density
(Sammouth et al. 2009). The fish body weight coefficient of variation was under $25 \%$.

Coefficient of variation for fish body weight, $W, C V=$ $100 \times$ Standard deviation/mean $W$.

The acclimation period in the experimental tanks was 27 days.

\subsection{Experimental growth period}

The experimental growth period started when a normal daily feed ingestion rate was observed for each tank. The $\mathrm{M}_{8}$, $\mathrm{M}_{20}, \mathrm{M}_{40}$ and $\mathrm{M}_{60}$ pellets were randomly assigned in triplicate to different tanks in the experimental room. The fish were fed daily for 54 consecutive days. All the fish were weighed individually three times (on days 0, 27 and 54). For biometric analysis, the fish were anesthetized (20-30 ppm) with clove essential oil (Eugenol ${ }^{\circledR}$ ) following $24 \mathrm{~h}$ of starvation (Kaiser et al. 2006).

The following indices and formulas were used to assess fish growth:

$$
\begin{aligned}
& \text { Specific growth rate }\left(\% \mathrm{day}^{-1}\right), \\
& \mathrm{SGR}=100\left(\ln W_{f}-\ln W_{i}\right) / t \\
& \text { Daily feed consumption }\left(\% \text { day }^{-1}\right), \\
& \text { DFC } \left.=100(W \mathrm{p}) /\left[\left(B_{i}+B_{f}\right) / 2\right) t\right] \\
& \text { Feed conversion ratio }\left(\mathrm{g} \mathrm{g}^{-1}\right), \mathrm{FCR}=W \mathrm{p} /\left(B_{f}-B_{i}\right)
\end{aligned}
$$

where $W_{i}$ and $W_{f}$ are respectively the initial and final average body weight $(\mathrm{g}), t$ the duration of the experiment (days), $W \mathrm{p}$ is the weight of dry feed ingested $(\mathrm{g})$, and $B_{i}$ and $B_{f}$ are the initial and final fish biomass $(\mathrm{g})$.

\subsection{Bath challenge with Vibrio anguillarum}

\subsubsection{Bacteria culture}

At the end of the feeding period, the fish $(n=320)$ were submitted to a bath challenge with a bacterium to assess their resistance to infection (Volpatti et al. 2013). The representative V62 strain of Vibrio anguillarum (kindly provided by Dr Breuil, Ifremer, France) was isolated from diseased European sea bass reared in farm located along the French Mediterranean 
coast. The strain was cultivated by the Montpellier Ifremer laboratory team using Zobell marine agar at $20{ }^{\circ} \mathrm{C}$ until constant exponential growth was achieved. After $48 \mathrm{~h}$, a colony was grown in a test tube containing $5 \mathrm{ml}$ Zobell liquid medium for one day at $20{ }^{\circ} \mathrm{C}$ with stirring at 250 rotations per minute. Two consecutive 1:40 and 1:20 culture dilutions were prepared respectively $48 \mathrm{~h}$ and $24 \mathrm{~h}$ later under the same conditions. The final colony concentration, evaluated using spectrophotometry $(630 \mathrm{~nm})$, was $10^{7}$ colony forming units (CFU) $\mathrm{ml}^{-1}$.

\subsubsection{Fish sampling for the bath challenge}

Bath exposure realistically simulates infection in farming conditions compared to intra-peritoneal injections in fish. At the end of the feeding period (54 days), all the fish (130.6 \pm $0.2 \mathrm{~g}$ ) were slightly anesthetized (100 ppm) after $24 \mathrm{~h}$ of starvation, with phenoxy-2-ethanol. Four 100-liter bath tanks were prepared with pure oxygen and no water renewal. Each bath tank received 20 tagged fish from each treatment $(n=80)$.

\subsubsection{Fish pathogenic bath challenge}

A culture volume of $800 \mathrm{ml}$ of Vibrio anguillarum $\left(10^{7} \mathrm{CFU} \mathrm{m}{ }^{-1}\right)$ was introduced into three bath tanks. No bacteria were added to the fourth bath tank considered to be the pathogenic challenge control. The fish were exposed for one hour with a charge of about $100 \mathrm{~kg} \mathrm{~m}^{-3}$. The four fish populations were then transferred into four larger tanks $\left(1 \mathrm{~m}^{3}\right)$ belonging to a specific pathogen-free RAS $\left(4.5 \mathrm{~m}^{3}\right)$. The "tank effect" factor was analysed statistically. The system effluents were treated by chlorination. Seawater temperature was maintained at $19.1 \pm 0.3{ }^{\circ} \mathrm{C}$ during the test period. Fish mortality was monitored twice daily during the subsequent 7 days $(168 \mathrm{~h})$. Dead fish were identified using the fish transponder tags.

\subsection{Statistical analysis}

The normal distribution of data and homoscedasticity were controlled using the Linear test and the Fisher-test, respectively (Microsoft ${ }^{\circledR}$ EXEL $^{\mathrm{TM}}$ ). For normally distributed data, differences were detected using ANOVA and the model $Y=$ $\operatorname{Var}_{1}+\operatorname{Var}_{2}+\varepsilon_{1 / 2}\left(\right.$ Statsoft ${ }^{\circledR}$ STATISTICA 8.0 $\left.{ }^{\mathrm{TM}}\right)$ where $\operatorname{Var}_{1}$ was the moist pellet effect, $\operatorname{Var}_{2}$ was the tank effect and $\varepsilon_{1 / 2}$ was the residual moist pellet/tank part. Growth data of the fish $\left(W_{f}-W_{i}\right)$ were analyzed statistically using the Generalized Linear Model and $Y=\operatorname{Var}_{1}+\operatorname{Var}_{2}\left(\operatorname{Var}_{1}\right)+\varepsilon_{1 / 2}$, tested using Tuckey's HSD test (Statsoft ${ }^{\circledR}$ STATISTICA 8.0 ${ }^{\mathrm{TM}}$ ). Daily feed consumption, SGR and FCR data did not meet statistical requirements and the analysis was performed using the nonparametric Wilcoxon test (Statsoft ${ }^{\circledR}$ STATISTICA 8.0 ${ }^{\mathrm{TM}}$ ). Fish mortality was analyzed using the Chi-squared test $\left(\chi^{2}\right)$ to detect significant differences between the bath tanks and treatments. Mortality means in percentage $(k)$ per treatment were converted using $y=\operatorname{Arcsin}(\sqrt{ } k)$, followed by comparison of groups using post hoc Fisher's Least Significant Difference (LSD) test $\left(\right.$ Statsoft ${ }^{\circledR}$ STATISTICA $8.0^{\mathrm{TM}}$ ). The $\mathrm{H}_{0}$ hypothesis considered there were no differences between mortality means and the level of significant difference was set at $5 \%(p \leqslant 0.05)$.

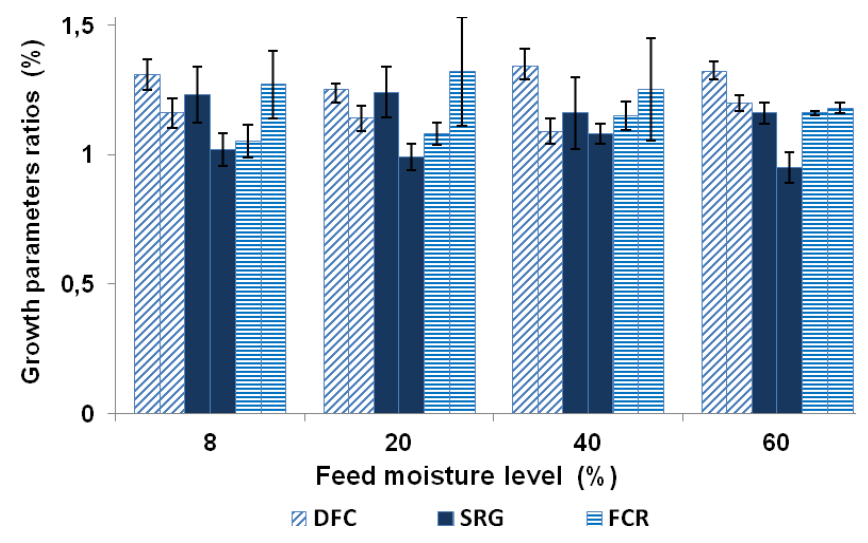

Fig. 2. Fish growth performances during the experiment (54-days) per feed moisture level (values $\pm \mathrm{SD}$ ). DFC: daily feed consumption $\left(\%\right.$ day $\left.^{-1}\right)$, SGR: specific growth rate $\left(\%\right.$ day $\left.^{-1}\right)$, FCR: feed conversion ratio $\left(\mathrm{g} \mathrm{g}^{-1}\right)$. The left column shows the first period (27 days) and the right column shows the second period (27 days).

\section{Results}

\subsection{Fish growth and rearing mortality}

In the control group, average fish weight was initially $72.7 \pm 17.9 \mathrm{~g}$ and it reached $133.3 \pm 29.4 \mathrm{~g}$ after 54 days. Individual fish weight gain was not significantly different between treatments (Table 1) including control $\left(\mathrm{M}_{8}\right.$, feed pellet with $8 \%$ moisture content). No significant differences were observed in the fish growth parameters DFC, SGR, and FCR with the different feeds during the whole experiment (Fig. 2). Fish size variability, expressed by the weight coefficient of variation, decreased with all feeds during the experiment. The average DFC was in an acceptable range from $1.0 \%$ to $1.1 \% \mathrm{day}^{-1}$ and pellet consumption was higher during the first period for all feed moisture levels. Feed conversion ratios were similar for all treatments and followed a gradient ranging from 1.16 $\left(\mathrm{M}_{8}\right)$ to $1.24\left(\mathrm{M}_{60}\right)$. Focused analyses during the two successive 27-day periods revealed a slightly better FCR with $\mathrm{M}_{8}$, with $\mathrm{M}_{8}>\mathrm{M}_{20}>\mathrm{M}_{40}=\mathrm{M}_{60}$ during the first period. All FCRs decreased during the second period except $\mathbf{M}_{60}$ which stayed the same and was ranked first. During the whole experiment, the SGR with all feeds was in the range of $1.0 \%$ to $1.1 \%$ day $^{-1}$. SGR was higher during the first period but not statistically different during the second period.

No mortality was observed during the acclimation period. During the experimental period rearing mortality was limited for $\mathrm{M}_{8}(3.4 \%), \mathrm{M}_{20}(4.1 \%), \mathrm{M}_{40}(3.4 \%)$ and very low for $\mathrm{M}_{60}$ $(0.7 \%)$.

\subsection{Pathogen challenge}

Oxygen percent saturation in the challenge RAS was $103.2 \pm 0.3 \%$ and was not limiting for fish physiology. The $\mathrm{pH}$ was $7.79 \pm 0.03$ and the oxido-reduction (redox) potential was $193 \pm 29 \mathrm{mV}$. During the challenge period, no mortality was observed in the non-infected control tank. The fish mortality observed in the three other infected tanks can be considered to be a response to infection. Mortality was observed during $168 \mathrm{~h}$ 
Table 1. Fish growth parameters (a 54-day rearing period) and moisture content (M \%) in feed pellets. Values are the mean of three replicate tanks \pm SD. AFW: Average fish weight, CV: Coefficient of variation in fish weight, DFC: Daily feed consumption. SGR: Specific growth rate, FCR: Feed conversion ratio, and mortality in rearing conditions.

\begin{tabular}{ccccc}
\hline & \multicolumn{4}{c}{ MOISTURE CONTENT IN FEED PELLETS } \\
\cline { 2 - 5 } & M 8 (Control) & M 20 & M 40 & M 60 \\
\cline { 2 - 5 } Number of fish & 144 & 146 & 144 & 147 \\
Initial AFW (g) & $72.69 \pm 17.88$ & $74.38 \pm 15.58$ & $72.20 \pm 14.34$ & $73.47 \pm 16.66$ \\
Final AFW (g) & $133.25 \pm 29.37$ & $131.65 \pm 25.83$ & $129.04 \pm 23.62$ & $128.68 \pm 27.51$ \\
Individual & $58.31 \pm 18.00$ & $56.44 \pm 12.61$ & $56.98 \pm 15.46$ & $55.51 \pm 26.11$ \\
weight gain (g) & $24.0 \pm 1.3$ & $24.2 \pm 1.8$ & $23.3 \pm 1.6$ & $22.7 \pm 1.1$ \\
Initial CV (\%) & $22.2 \pm 1.6$ & $19.3 \pm 0.4$ & $21.7 \pm 3.8$ & $21.3 \pm 0.4$ \\
Final CV (\%) & $1.07 \pm 0.03$ & $1.05 \pm 0.04$ & $1.09 \pm 0.05$ & $1.10 \pm 0.03$ \\
DFC (\%) & $1.12 \pm 0.03$ & $1.06 \pm 0.05$ & $1.08 \pm 0.05$ & $1.04 \pm 0.06$ \\
SGR (\%) & $1.16 \pm 0.02$ & $1.24 \pm 0.12$ & $1.25 \pm 0.08$ & $1.24 \pm 0.02$ \\
FCR (g g ${ }^{-1}$ ) & 5 & 6 & 5 & 1 \\
Rearing mortality & 5 & & & \\
(fish) & & &
\end{tabular}

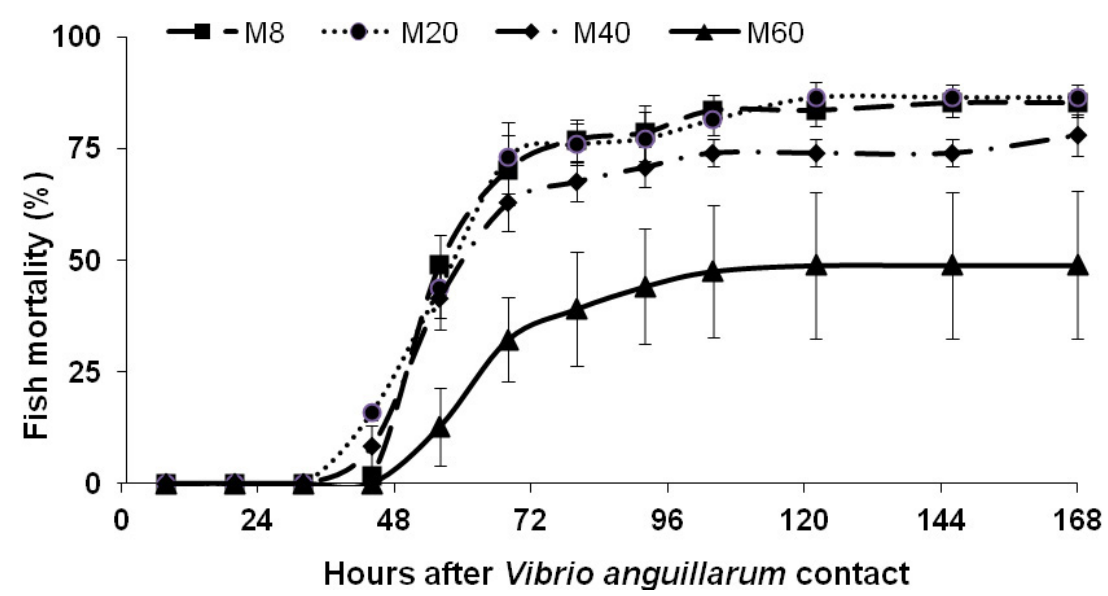

Fig. 3. Cumulated fish mortality kinetics in percentage (means \pm SEM) per feed moisture level (M8: Control pellets) in the hours after Vibrio anguillarum contact. Each bath tank $(n=3)$ contained 20 tagged fish from each treatment.

(7 days). The first death was recorded $44 \mathrm{~h}$ after the challenge. Vibrio anguillarum infection causes lethargy, exophthalmia, skin lesions, internal organ haemorrhages and finally death in non-resistant fish. The total mortality rate was 178 fish, i.e. $74 \%$ of the total challenged population $(n=240)$. No significant differences in mortality were observed between the three infected tanks. The absence of a "tank effect" allowed us to compare the four treatments in the three mixed populations. Mortality peaked at 19 fish with the $\mathrm{M}_{8}$ pellets $56 \mathrm{~h}$ after the infection and 18, 13 and 12 fish $12 \mathrm{~h}$ later with the $\mathrm{M}_{20}, \mathrm{M}_{40}$, and $\mathrm{M}_{60}$ pellets, respectively. Fish mortality kinetics was less important with the $\mathrm{M}_{60}$ pellets (Fig. 3). Half the deaths occurred about 56 hours after contact with the Vibrio bacterium with all pellets except the $\mathrm{M}_{60}$ pellets with which half the deaths occurred at around $68 \mathrm{~h}$. An initial statistical analysis revealed a difference between the four feeding conditions. Focused analysis using Tuckey's HSD post-hoc test showed that the final mortality rate $(168 \mathrm{~h})$ with the $\mathrm{M}_{60}$ treatment $(49 \pm 15 \%)$ was significantly lower $(p<0.05)$ than with the $\mathrm{M}_{40}(78 \pm 2 \%)$, $\mathrm{M}_{20}(86 \pm 6 \%)$ and $\mathrm{M}_{8}(85 \pm 3 \%)$ pellets. The $\mathrm{M}_{40}$ mortality rate was significantly lower $(p<0.05)$ than the $\mathrm{M}_{20}$ and $\mathrm{M}_{8}$ rates from 104 to $146 \mathrm{~h}$ but not at the end of the experiment.

\section{Discussion}

\subsection{Experimental growth performance}

This study was based on the hypothesis that moisturized feed could have a beneficial effect on fish growth through osmoregulatory cost reduction. Fish growth is directly linked to feed composition, rearing system and water quality. Water parameters in our experimental RAS were in line with regular rearing conditions for European sea bass (Dosdat et al. 2003). The fish body weight coefficient of variation was lower at the end of the experiment for all treatments and contributed to fish population homogeneity. However, the $\mathrm{M}_{8}-\mathrm{SGR}$ and FCR were better under limited feeding conditions than in previous experiments in the same facility (Deviller et al. 2004; Mladineo et al. 2010). All these parameters indicate that our feeding strategy was correct. No significant differences in DFC, SGR and FCR were observed between the various feeds during 54 days. Generally duplication of initial weight is considered the bare minimum but the availability of the experimental tools did not allowed us to continue the experiment longer. In view of the Dicentrachus labrax growth model in 
RAS, seven days more were required to reach this goal. Increasing dietary water content had no effect on European sea bass growth when the fish weighed between $73 \mathrm{~g}$ and $133 \mathrm{~g}$.

Our results in this growth range do not support the better growth hypothesis with moisturized feed although some studies on marine fish species report better growth. This was the case for adult Dentex dentex fed with $\mathrm{M}_{20}$ pellets for 151 days (Chatzifotis et al. 2005) or fingerlings fed with $\mathrm{M}_{25}$ pellets for 120 days (Efthimiou et al. 1994). Psetta maxima juveniles fed with $\mathrm{M}_{81}$ prey for 120 days showed better SGRs and FCRs (Grove et al. 2001). A slight difference in FCR in favour of $\mathrm{M}_{32}$ feed was observed for Lates calcarifer fed for 130 days (Chou 1984). A significant difference was observed in the SGR with the profile $\left(\mathrm{SGR}_{\mathrm{M} 40}=\mathrm{SGR}_{\mathrm{M} 20}\right)>\mathrm{SGR}_{\mathrm{M} 7}$ being reported for Seriola dumerilii and a significant difference in FCR in favour of $\mathrm{M}_{20}$ feed was observed during a 126-day experiment (Papadakis et al. 2008). Similar results were observed with Pampus argenteus fingerlings fed with $\mathrm{M}_{25}$ feed for 82 days (Cruz et al. 2000). However, no significant differences were found between Sebastes schlegeli larvae fed with $\mathrm{M}_{36}$ feed for 82 days (Lee et al. 2000), or Scophthalmus maximus fingerlings fed with $\mathrm{M}_{8}, \mathrm{M}_{20}, \mathrm{M}_{40}$ and $\mathrm{M}_{75}$ feed for 54 days (Bromley 1980) or Solea solea fed with $\mathrm{M}_{7}, \mathrm{M}_{20}, \mathrm{M}_{30}, \mathrm{M}_{40}, \mathrm{M}_{50}$ and $\mathrm{M}_{65}$ feed for 66 days (Schneider 2009).

Our study was divided in two consecutive 27-day periods. The growth parameters with all the feeds were lower in the second period compared to the first, except $\mathrm{FCR}_{\mathrm{M} 60}$ which remained stable. This observation could indicate that in sea bass, the feed conversion process starts being efficient after 7 weeks of feeding with moist diet. Taking into consideration previous studies, significant results on growth parameters might be obtained after a study period of 110 days. Our experiment was undoubtedly too short even if a trend in favour of $\mathrm{FCR}_{\mathrm{M} 60}$ became visible but remained non-significant.

\subsection{Nutrient assimilation}

Fish drinking rates and digesta moisturizing mechanisms concern both fresh water and marine fish (Kristiansen and Rankin 2001; Varsamos et al. 2004). Dietary moisture content had a significant effect on pink salmon (Oncorhynchus gorbuscha) growth (Higgs et al. 1985). The FCR is strongly dependent on the efficiency of the digestive process which is based on the digestive bacteria in the mucus layer and digestive enzyme activity. The digestibility coefficients of processed and formulated fish feeds are 5\% to $10 \%$ lower than those of natural food. The digestive process might be limited by the high energy of dry formulated feed, which may rapidly saturate stomach assimilation sites (Jobling 1986). The FCR M60 $_{1}$ stability compared to the other treatments suggest that dietary moisture may play a role in nutrient digestibility and probably represents an environmental change for the digestive bacterial community located in the gut of fish.

The moisturized pellets were brighter in colour than the commercial pellets (control) but buoyancy was the same. With Korean rockfish, Sebastes schlegelii (Lee et al. 2000), Chinook salmon, Oncorhynchus tshawytscha (Hughes and Barrows 1990) and Salmo salar (Oehme et al. 2014) feed intake was more dynamic when the pellet water content was increased.
This behaviour was also observed in this study during feeding of the $\mathrm{M}_{60}$ fish. It could be due to better pellet visibility in a dark tank. Visual detection of inert prey by the fish would be the main factor affecting feeding behaviour. Alternatively, moisturizing the pellets might increase their palatability. Moisture-related pellet dilation could promote nutrient flavour spreading in the tank and increase fish appetite sensitivity. This could explain the faster feed intake in the $\mathrm{M}_{60}$ tank compared to the other tanks.

\subsection{Rearing mortality}

Fish mortality during the rearing period was lower in the $\mathrm{M}_{60}$ tank (one died fish only) than in the other tanks (5-6 fish). All the fish were acclimated for 27 days before the growth experiment and no mortality was recorded during this period. The mortality observed in our stable experimental RAS could be associated with a specific feed moisture-related event. Rearing mortality decreased when feed water content increased in silver pumfret (Pampus argenteus) fed with $\mathrm{M}_{10}$ (25\%) and $\mathrm{M}_{25}$ feed (0\%) (Cruz et al. 2000), in Dentex dentex (Chatzifotis et al. 2005; Efthimiou et al. 1994) and in barramundi (Lates calcarifer) fed with $\mathrm{M}_{32}$ feed (10\%) (Chou 1984). Fish survival could be linked to dietary quality which has an impact on the protective bacterial community (Wong et al. 2013). Rearing mortality is strongly linked to the system (cage, flowthrough system or RAS) but it represents a small economic loss compared to loss caused by bacterial infection.

\subsection{Resistance to bacterial infection}

Vibrio anguillarum adheres to the fish gut (Horne and Baxendale 1983). The fish from the $\mathrm{M}_{60}$ tank showed better resistance to Vibrio anguillarum infection. The fish intestine plays an recognized osmoregulatory role by absorbing fluid to compensate for water losses in a hyperosmotic environment (Whittamore 2012). The fish gastrointestinal tract assimilates $63 \%$ of water ingested by drinking or eating moist feed (Bucking et al. 2011). The intestinal mucus of fish contains various indigenous bacterial colonies and is a favourable ecosystem for Vibrio anguillarum multiplication (Westerdahl et al. 1994). The mucus layer is permanently in contact with the rearing water. The Vibrio bacteria found in fish mucus come exclusively from ingested water (Olsson et al. 1992; Spanggaard et al. 2001) and can still be observed in the mucus layer 6 hours after ingestion despite the action of the bile and a low $\mathrm{pH}$. Bacterial concentrations and families in the fish gut may play an important role against a Vibrio infection. A gastrointestinal tract hosting protective bacteria is a barrier against pathogens and $60 \%$ of the protective bacteria are able to inhibit exogenous pathogenic bacteria and $28 \%$ specifically inhibit Vibrio anguillarum (Westerdahl et al. 1991).

The adhesion of Vibrio anguillarum to the fish gut implies a partially non-specific mechanism such as a hydrophobic interaction related to specific probiotics (Grzeskowiak et al. 2011). A hydrophobic mechanism of adhesion of the bacterium to the mucus layer of the fish could explain the results in the $\mathrm{M}_{60}$ conditions and the shift in the mortality peak to $24 \mathrm{~h}$ 
after the other conditions. Pathogenic bacteria present in water ingested during the challenge period may have had more difficulties invading the mucus layer of fish because of the moisture in the feed. This could explain the gradient results observed with increasing feed water contents.

In addition to the Vibrio adherence and protective bacteria aspect, another factor may be investigated. Digestive tract mucus integrity is essential for fighting undesirable pathogens (Buddington et al. 1997; Svendsen and Bogwald 1997). Moisturizing formulated feed softens the feed proportionally to the amount of water added. Softening pellets could reduce the abrasive action of dry pellets on the mucus layer. This observation was already reported in farm-reared Dicentrarchus labrax fed with commercial pellets and compared to fish from fishing fed with natural prey with $70-80 \%$ water content. Pronounced hypertrophy of the intestinal folds and abrasion-induced degeneration of the epithelium has been demonstrated in aquaculture fish (Deplano et al. 1991).

Mucus integrity, site conversion of nutrients, a protective bacterial community and Vibrio difficulty in adhering to the intestine due to the moisture content of the feed could explain the noteworthy results obtained following the challenge of fish fed with pellets with the highest water content.

\section{Conclusion}

In our study, no statistical difference in Dicentrarchus labrax growth was observed between the dry and moisturized diets. A longer rearing period, probably more than 54 days, would be necessary to make demonstrate the advantages of feeding fish with moisturized pellets.

The most important result concerns sea bass resistance to Vibrio anguillarum infection. A positive and progressive effect on fish resistance was observed above $20 \%$ of moisture in pellets. This experiment ask the question of development the bacterial protective community in the intestinal mucus, when the water content of the pellets reached $60 \%$, i.e. almost the water content of natural prey.

Feed manufacturers and scientists have explored the possibility of including prebiotics, probiotics, yeast or specific bacteria into dry feed just before distribution to fish in the aim of increasing growth and treating or preventing fish diseases. Given that rearing conditions are different on each farm and depend on fish species, life stage, the environment and local diseases treatment to improve growth or immunity has to be specifically elaborated for each farm situation. Moisturized pellets could be combined with compounds of interest using water as the medium with a positive effect on fish gut integrity. Future experiments could focus on the relationship between the mucus layer, water and specific bacteria to optimize feed conversion efficiency and reduce fish loss during the rearing period, in the aim of making fish farming ecological, economically viable and sustainable.

Acknowledgements. This study was carried out with grants from ERG "Aquafood". The author is grateful to the Palavas les Flots IFREMER team, in particular M.J. Debos for the library research and B. Rollin, B. Devoguie and S. Triplet for their continued technical assistance. The Ifremer station in Montpellier was also of great assistance for the pathogenic agent cultivation, especially A. Vergnes. Thanks to the Imares Research Institute in Netherlands, particularly to O. Schneider, J. Vanderheul, E. Schram, J. Kars for their opinions and fruitful exchanges and $\mathrm{H}$. Zeedijk for the administrative management. The author pays tribute to Dr. Luigi Michaud friend and Italian scientist from the University of Messina who died in January 2014 in the Newfoundland Bay (Antarctic) in the performance of his duties during a scientific mission.

\section{References}

Bendschneider K., Robinson R.J., 1952, A new spectrophotometric method for the determination of nitrite in sea water. J. Mar. Res. 11, 87-96.

Bromley P., 1980, The effect of dietary water content and feeding rate on the growth and food conversion efficiency of turbot (Scophthalmus maximus L.). Aquaculture 20, 91-99.

Bucking C., Fitzpatrick J.L., Nadella S.R., McGaw I.J., Wood C.M., 2011, Assimilation of water and dietary ions by the gastrointestinal tract during digestion in seawater-acclimated rainbow trout. J. Comp. Physiol. B- Biochem. Syst. Environ. Physiol. 181, 615630.

Buddington R.K., Krogdahl A., BakkeMcKellep, A.M., 1997, The intestines of carnivorous fish: structure and functions and the relations with diet. Acta Physiol. Scand. 161, 67-80.

Chatzifotis S., Papadakis A.E., Divanach P., 2005, Effect of dietary water on growth of dentex Dentex dentex. Fish. Sci. 71, 12431248.

Chou R., 1984, The effect of dietary water content on the feed intake, food conversion efficiency and growth of young sea bass (Lates calcarifer). Singapore J. Primary Ind. 12, 120-127.

Cruz E.M., Almatar S., Abdul Elah K., Al-Yaqout A., 2000, Preliminary studies on the performance and feeding behavior of silver pomfret (Pampus argenteus Euphrasen) fingerling fed with commercial feed and reared in fiberglass tanks. Asian Fish. Sci. 13, 191-199.

Deplano M., Connes R., Diaz J.P., 1991, Postvalvular enterocytes in feral and farm-reared sea bass Dicentrarchus labrax - hypervacuolization related to artificial feed. Dis. Aquat. Org. 11, 9-18.

Deviller G., Aliaume C., Nava M.A.F., Casellas C., Blancheton J.P., 2004, High-rate algal pond treatment for water reuse in an integrated marine fish recirculating system: effect on water quality and sea bass growth. Aquaculture 235, 331-344.

Dosdat A., Person-Le Ruyet J., Coves D., Dutto G., Gasset E., Le Roux A., Lemarie G., 2003, Effect of chronic exposure to ammonia on growth, food utilisation and metabolism of the European sea bass (Dicentrarchus labrax). Aquat. Living Resour. 16, 509520.

Efthimiou S., Divanach P., Rosenthal H., 1994, Growth, food conversion and agonistic behavior in commun dentex (Dentex dentex) juveniles fed on pelleted moist and dry diets. Aquat. Living Resour. 7, 267-275.

European-Union, 2009, Regulation (EC) No 767/2009 of the European Parliament and of the Council of 13 July 2009 on the placing on the market and use of feed, amending European Parliament, art 11, paragrah 5. Official Journal of the European Union L 229, 1 September 2009, pp. 1-28.

Grove D., Genna R., Paralika V., Boraston J., Hornyold M.G., Siemens R., 2001, Effects of dietary water content on meal size, daily food intake, digestion and growth in turbot, Scophthalmus maximus (L.). Aquac. Res. 32, 433-442. 
Grzeskowiak L., Carmen Collado M., Vesterlund S., Mazurkiewicz J., Salminen S., 2011, Adhesion abilities of commensal fish bacteria by use of mucus model system: quantitative analysis. Aquaculture 318, 33-36.

Gwyther D., Grove D.J., 1981, Gastric emptying in Limanda limanda and the return of appetite J. Fish Biol. 18, 245-259.

Heuer R.M., Esbaugh A.J., Grosell M., 2012, Ocean acidification leads to counterproductive intestinal base loss in the Gulf toadfish (Opsanus beta). Physiol. Biochem. Zool. 85, 450-459.

Higgs D.A., Markert J.R., Plotnikoff M.D., McBride J.R., Dosanjh B.S., 1985, Development of nutritional and environmental strategies for maximazing the growth and survival of juveniles of pink Salmon (Onccorhyncus gorbuscha). Aquaculture 47, 113-130.

Horne M.T., Baxendale A., 1983, The adhesion of Vibrio anguillarum to host tissue and its role in pathogenesis. J. Fish Dis. 6, 461-471.

Hughes S.G., Barrows R., 1990, Measurements of the abilities of cultured fishes to moisturize their digesta. Comp. Biochem. Physiol. A 96, 109-111.

Jobling M., 1986, Gastrointestinal overload - A problem with formuleted feeds. Aquaculture 51, 257-263.

Kaiser H., Brill G., Cahill J., Collett P., Czypionka K., Green A., Orr K., Pattrick P., Scheepers R., Stonier T., Whitehead M.A., Yearsley R., 2006, Testing clove oil as an anaesthetic for longdistance transport of live fish: the case of the Lake Victoria cichlid Haplochromis obliquidens. J. Appl. Ichthyol. 22, 510-514.

Kaushik S.J., Coves D., Dutto G., Blanc D., 2004, Almost total replacement of fish meal by plant protein sources in the diet of a marine teleost, the European seabass, Dicentrarchus labrax. Aquaculture 230, 391-404.

Kristiansen H.R., Rankin J.C., 2001, Discrimination between endogenous and exogenous water sources in juvenile rainbow trout fed extruded dry feed. Aquat. Living Resour. 14, 359-366.

Lee S.M., Hwang U.G., Cho S.H., 2000, Effects of feeding frequency and dietary moisture content on growth, body composition and gastric evacuation of juvenile Korean rockfish (Sebastes schlegeli). Aquaculture 187, 399-409.

Mladineo I., Bocina I., Przybyla C., Fievet J., Blancheton J.P., 2010, Fish growth and health aspects of sea bass (Dicentrarchus labrax) reared in standard vs. high rate algal pond recirculation systems. Aquat. Living Resour. 23, 217-224.

Mouchet M.A., Bouvier C., Bouvier T., Troussellier M., Escalas A., Mouillo, D., 2012, Genetic difference but functional similarity among fish gut bacterial communities through molecular and biochemical fingerprints. FEMS Microbiol. Ecol. 79, 568-580.

Nikolopoulou D., Moutou K.A., Fountoulaki E., Venou B., Adamidou S., Alexis M.N., 2011, Patterns of gastric evacuation, digesta characteristics and $\mathrm{pH}$ changes along the gastrointestinal tract of gilthead sea bream (Sparus aurata L.) and European sea bass (Dicentrarchus labrax L.). Comp. Biochem. Physiol. AMolecular Integrative Physiology 158, 406-414.

Oehme M., Aas T.S., Olsen H.J., Sorensen M., Hillestad M., Li Y., Asgard T., 2014, Effects of dietary moisture content of extruded diets on physical feed quality and nutritional response in Atlantic salmon (Salmo salar). Aquac. Nutr. 20, 451-465.

Olsson J.C., Westerdahl A., Conway P.L., Kjelleberg S., 1992, Intestinal colonization potential of turbot (Scophthalmus maximus) and dab (Limanda limanda) associated bacteria with inhibitory effect against Vibrio anguillarum. Appl. Environ. Microbiol. 58, 551-556.
Papadakis I.E., Chatzifotis S., Divanach P., Kentouri M., 2008, Weaning of greater amberjack (Seriola dumerilii Risso,1810) juveniles from moist to dry pellet. Aquac. Int. 16, 13-25.

Person-Le Ruyet J., Mahe K., Le Bayon N., Le Delliou H., 2004, Effects of temperature on growth and metabolism in a Mediterranean population of European sea bass, Dicentrarchus labrax. Aquaculture 237, 269-280.

Pichavant K., Person-Le-Ruyet J., Le Bayon N., Severe A., Le Roux A., Boeuf G., 2001, Comparative effects of long-term hypoxia on growth, feeding and oxygen consumption in juvenile turbot and European sea bass. J. Fish Biol. 59, 875-883.

Quinton R., 1912, L'eau de mer, milieu organique. Masson \& Cie. Editeurs, Paris.

Rana K., Siriwardena S., Hassan M., 2009, Impact of rising feed ingredient price on aquafeeds and aquaculture production. Fisheries and aquaculture FAO Tech. Pap.

Ruohonen K., Grove D.J., McIlroy J.T., 1997, The amount of food ingested in a single meal by rainbow trout offered chopped herring, dry and wet diets. J. Fish Biol. 51, 93-105.

Ruohonen K., Vielma J., Grove D.J., 1998a, Comparison of nutrient losses into the water from rainbow trout culture based on fresh Baltic herring, moist and dry diets. Aquac. Int. 6, 441-450.

Ruohonen K., Vielma J., Grove D.J., 1998b, High dietary inclusion level of fresh herring impairs growth of rainbow trout, Oncorhynchus mykiss. Aquaculture. 163, 263-273.

Sammouth S., d'Orbcastel E.R., Gasset E., Lemarie G., Breuil G., Marino G., Coeurdacier J.L., Fivelstad S., Blancheton J.P., 2009, The effect of density on sea bass (Dicentrarchus labrax) performance in a tank-based recirculating system. Aquac. Eng. 40, 72 78.

Schneider O., van der Heul J., Schram E., Schrama J., Sæther B.S., 2009, Increased moisture of pelleted dry diets improves sole growth, New research frontiers - novel approaches for evolving needs, Trondheim, 14-17 August 2009.

Solorzano L., 1969, Determination of ammonia in natural waters by the phenolhypochlorite method. Limnol. Oceanogr. 14, 799-801.

Spanggaard B., Huber I., Nielsen J., Sick E.B., Pipper C.B., Martinussen T., Slierendrecht W.J., Gram, L., 2001, The probiotic potential against vibriosis of the indigenous microflora of rainbow trout. Environ. Microbiol. 3, 755-765.

Svendsen Y.S., Bogwald J., 1997, Influence of artificial wound and non-intact mucus layer on mortality of Atlantic salmon (Salmo salar L.) following a bath challenge with Vibrio anguillarum and Aeromonas salmonicida. Fish Shellfish Immunol. 7, 317-325.

Tytler P., Tatner M., Findlay C., 1990, The ontogeny of drinking in the rainbow trout, Onchorhynchus mykiss (Walbaum). J. Fish Biol. 36, 867-875.

Van Ham E.H., Berntssen M.H.G., Imsland A.K., Parpoura A.C., Bonga S.E.W., Stefansson S.O., 2003, The influence of temperature and ration on growth, feed conversion, body composition and nutrient retention of juvenile turbot (Scophthalmus maximus). Aquaculture 217, 547-558.

Varsamos S., Bonga S.E.W., Charmantier G., Flik C., 2004, Drinking and $\mathrm{Na}+\mathrm{K}+$ ATPase activity during early development of European sea bass, Dicentrarchus labrax - Ontogeny and shortterm regulation following acute salinity changes. J. Exp. Mar. Biol. Ecol. 311, 189-200. 
Volpatti D., Bulfon C., Tulli F., Galeotti M., 2013, Growth parameters, innate immune response and resistance to Listonella (Vibrio) anguillarum of Dicentrarchus labrax fed carvacrol supplemented diets. Aquac. Res. 45, 31-44.

Westerdahl A., Olsson J.C., Kjelleberg S., Conway P.L., 1991, Isolation and characterization of turbot (Scophthalmus maximus) associated bateria with inhibitory effects against Vibrio anguillarum. Appl. Environ. Microbiol. 57, 2223-2228.

Westerdahl A., Olsson J.C., Conway P.L., Kjelleberg S., 1994, Characterization of turbot (Scophthalmus maximus) associated bacteria with inhibitory effects against the fish pathogen Vibrio anguillarum. Acta Microbiol. Immunol. Hung. 41, 403-409.
Whittamore J.M., 2012, Osmoregulation and epithelial water transport: lessons from the intestine of marine teleost fish. J. Comp. Physiol. B-Biochem. Syst. Environm. Physiol. 182, 1-39.

Wong S., Waldrop T., Summerfelt S., Davidson J., Barrows F., Kenney P.B., Welch T., Wiens G.D., Snekvik K., Rawls J.F., Good C., 2013, Aquacultured rainbow trout (Oncorhynchus mykiss) possess a large core intestinal microbiota that is resistant to variation in diet and rearing density. Appl. Environ. Microbiol. $79,4974-4984$.

Wood E.D., Armstrong F.A.J., Richards F.A., 1967, Determination of nitrate in sea water by 120 cadmium-copper reduction to nitrite. $\mathrm{J}$. Mar. Biol. Assoc. UK 47, 23-31. 